\title{
Innovation of Financial Management Refinement of Public Hospital under the Background of Compensation Mechanism Reform
}

\section{Li Huifeng}

\author{
Department of Economics and Management, Guangdong Vocational and Technical College, \\ Foshan, Guangdong, 528000
}

Key words: public hospital; compensation mechanism reform; financial management refinement

\begin{abstract}
The reform of compensation mechanism is the focus and difficulty of public hospital reform in recent years. Although the reform of compensation mechanism brings new development opportunities for the development of public hospitals, the development of opportunities often hides new development challenges, especially in public hospital financial management. Today, with the reform and innovation, the provincial public hospital compensation mechanism reform is in full swing, for which during this period concerned the public hospital as the main body, the compensation mechanism for the reform, to reform the core content of financial management as the main content to explore the public hospital finance development, which is very conducive to the implementation of public hospital compensation mechanism reform, and is conducive to the domestic public hospitals continuous, scientific and modern development, to reduce the risk of domestic doctors and patients disputes, to avoid medical treatment. These problems pose a threat to social harmony and stability.
\end{abstract}

\section{Introduction}

As a social welfare organization, the development results of public hospitals are closely related to the settlement of domestic livelihood problems. As with other nonprofit organizations in the community, the promotion of medical standards, technology, sustainable and modern development of public hospitals will also be hampered by the shortage of funds. To eliminate the obstacles to development and reform of the compensation mechanism, making a large extent to ease the pressure on public hospitals. Financial management as an important part of hospital management, good financial management will help the hospital to improve the use of funds, planning and monitoring capabilities, but also for the development of the hospital to provide decision-making basis and human logistics support. With the deepening of the financial management mechanism reform, in the financial management, the public hospital respected the extensive management model is now difficult to promote the implementation of the contents of the reform and implementation of how to develop a situation with the compensation mechanism reform and mutual response. The 
financial management model of collaborative management has become the development problem that must be faced and solved during the reform of public hospitals. Based on the development needs of public hospital compensation mechanism reform, the meticulous development of financial management will be the first choice for its future development.

\section{The issues of the public hospital financial management under compensation mechanism reform}

Although many public hospitals have begun to implement the relevant content, in view of the implementation of compensation mechanism reform, the hospital department for the understanding of the relevant content in depth has yet to be improved, the financial management concept is relatively old, and financial management awareness is relatively weak. Under the common promotion, the competitiveness of public hospitals has improved, but the income growth also makes it not careful planning, ignoring the cost of budget and analysis, cost accounting. The decline of management consciousness to a large extent restricts the further implementation of the reform of the compensation mechanism, but also reflects the current level of public hospital financial management personnel personal quality problems. As we all known, public hospitals in the market competition have the natural advantages, so they do not need to worry about survival problems, for which many public hospital staff will focus on personal work and nursing care, consider financial management as a secondary, neglect the importance of financial management to its development. As the saying goes, "No rules no standards ", because the hospital lack of management of financial personnel, the quality of the relevant staff is reasonable, but not conducive to the implementation of public hospitals reform work. In addition, the current domestic public hospitals are also a lack of unified HIS construction norms and technical standards, the information between the various departments of the hospital cannot be shared, but also greatly affected the overall cost of the hospital accounting control and co-ordination arrangements.

\section{The necessity of the physical analysis of public hospitals based on the financial fine management}

In view of the financial management of institutions, the Chinese Ministry of Finance as early as 2008 put forward to strengthen the scientific and meticulous management requirements. Financial management of the refinement is through the implementation of precise decision-making, accurate planning, precise control, accurate assessment, to improve management efficiency and increase economic efficiency of a management model. In the traditional financial management ideas, the financial work is to reimburse, do accounts, do statements, through the accounting check the 
balance of payments, evaluation of economic efficiency, strong procedures. Today, the increasingly fierce competition in the social market, the major business requirements for the financial has not only satisfied with the accounts clear, accurate calculation, but through the financial write-in, for the development of corporate strategy to provide a reference to achieve financial management fine development, which requires the financial staff not only in the work of the accounts, but also have a standardized and rigorous process and a comprehensive system, in improving efficiency under the premise of improving quality and efficiency.

As a major source of income for the early development of public hospitals, drug bonus is an important part of the income of public hospitals. It is closely related to all the staff of the hospital, but it is also an important fuse for doctors and patients. It is not conducive to the health, sustainable development, to this end, during the reform of the compensation mechanism, the state explicitly abolished the drug bonus system, although a large extent to reduce the income of public hospitals, which is the voice of the people and the needs of national medical business stability, sustained development. To conscientiously implement the relevant aspects of the reform of the compensation mechanism, the current domestic public hospitals have canceled the drug bonus. The public hospital financial income has changed from the original three (drug income, medical service income and financial subsidies income) into two (Medical service income and financial subsidy income). Also, the source of financial revenue sources less, making the original public hospital crude financial management approach to the development of the increasingly prominent, innovation and innovation, which is imperative.

\section{The model construction of the public hospital financial fine management under compensation mechanism reform}

Nowadays, the content of the reform mechanism has been successfully implemented. As an important component of the hospital, it should achieve the development of financial management in the refinement of the development of public hospitals to promote the contribution, to straighten out the development of ideas, to plan the financial management of the fine development of the line, during the specific work it can be carried out from two aspects: First, the financial assessment, in the refinement of the concept, the hospital financial management of content refinement and classification, highlighting key projects, paying attention to key projects, abandoning the early financial management ideas, will be more content into the scope of financial management assessment to expand. Second, establishing efficiency goals, due to reduced income sources, financial management in the process of implementation of fine management principles should pay more attention to the hospital's budget, analysis, accounting, control and other related work carried 
out, and give a reference for hospital development, which can be based on the actual development of the hospital every month to establish short, medium and long term benefits to other departments of the hospital term work carried out to make the guidance.

From the view of healthy operation and economic benefits of public hospitals, the hospital's overall financial budget is a very critical part that is to determine the economic benefits of the premise of the work. The significance of the financial budget is not only the accurate estimate of the operating costs, but also the overall planning of the hospital and the implementation of the decision-making to provide a scientific theoretical basis, which also shows the importance of financial management. Financial management of the refinement is in the budget and by the budget to provide a basis for accurate positioning, excellence, clear objectives, assessment refinement, as to improve efficiency, to eliminate the waste of the reference standard. But given the public hospital does not attach importance to the financial management work, if the reform mechanism is in the depth of the reform period, through the hospital financial management of the fine development of the hospital to make a wide range of development, to solve the problem of talent is the key.

Development ideas, planning a good financial management of the hospital after the development of fine lines, should also increase the relevant personnel training. In contrast, many private medical institutions and drug manufacturers in the financial management of the fine management use more than public hospitals. So,in the related personnel training, the hospital can make full use of their own social status advantages, and government agencies can strengthen the exchanges with other social organizations talents, or through the way of assignment to the working financial management personnel to provide opportunities for learning, so that during practice to learn and master more involved in financial refinement knowledge management.

Development practice shows that if you want to achieve the development of financial management development of the fine, the traditional manual accounting is difficult to achieve, because it needs to integrate into a certain modern technology as a support. Since entering the 21st century, computer network technology has become an indispensable hardware support for the financial management of major social enterprises, not only conducive to the realization of financial management, but also can effectively improve the efficiency of financial accounting. In addition, personnel training should also rely on compensation mechanisms to reform and development opportunities for financial management of technological development of acute innovation, into the computing network technology. First, the integration of modern computer technology can make the cumbersome data simplified, greatly reducing the workload of statistical calculations. Financial refinement management needs to set goals, cost budget and accounting, full control, computer technology that can make each job set a good program to help people faster and more accurately to 
complete these tasks, to avoid mistakes caused by human error. Second, the use of computer network and automation, and the development of implant functional science advanced hospital cost accounting management software system can integrate the hospital departments, departments of the financial accounting well, not only to ensure that the hospital cost of medical cost of the unified and standardized, but also to improve cost efficiency and quality of hospital, so that the cost of accounting can be a strong reference data and reliable decision-making basis for the overall efficiency of the hospital.Third, the hospital can also use the computer network technology to further improve the financial operation of the information management platform, in the development of material management systems, fixed assets systems, technology and other subsystems, through the integration of information systems on a regular basis to evaluate operational efficiency to control the cost increase, to avoid waste, and ultimately to achieve the purpose of improving efficiency.

\section{Reference:}

[1] Tang Renwu. Xi Jinping Reform Strategic Thinking Characteristics [J]. People's Forum .2013,36: 14-15

[2] Su Hui. On the Financial Management of Public Hospitals [J]. Modern Economic Information. 2013,08: 304-305

[3] Guo Yuxia. New Medical Reform under the Background of Public Hospital Cost of Fine Management Policies and Recommendations [J]. Times Finance .2014,10: 226,239

[4] Tan Lin. Innovation of Public Hospital Financial Management Based on Compensation Mechanism Reform [J]. Time Finance .2014,10: 190 